\title{
Formación Permanente de los Docentes como Referente de la Calidad Educativa
}

\author{
Autora: Johana Carolina Peña Lozada \\ Universidad Nacional Experimental "Rafael María Baralt", UNERMB \\ johanacarol@yahoo.com \\ Trujillo, Venezuela
}

\section{Resumen}

El presente artículo de revisión bibliográfica pretende hacer una reflexión para caracterizar la Formación Permanente de los Docentes como Referente de la Calidad Educativa, a través de una revisión documental, a fin de realizar una valoración del componente formación permanente bajo el esquema de la calidad educativa, el análisis apunta a consideraciones hechas por distintos autores, en los aspectos más relevantes, se hace notorio e imperativo la inclusión de políticas, planes y programas de acuerdo a la formación permanente del docente para la consecución de todos los objetivos que persigue la educación en los diferentes espacios que la conforman involucrando la praxis del docente en su accionar con miras a una mejor calidad educativa.

Palabras clave: formación permanente; docente; calidad educativa. 


\section{Permanent Training of Teachers as a Reference to Educational Quality}

\section{Abstract}

The present article of bibliographical revision intends to make a reflection to characterize the Permanent Formation of the Teachers as Referent of the Educational Quality, through a documentary revision, in order to realize an evaluation of the component permanent formation under the scheme of the educational quality, The analysis points to considerations made by different authors, in the most relevant aspects, it becomes notorious and imperative to include policies, plans and programs according to the ongoing training of the teacher to achieve all the objectives pursued by education in the Different spaces that comprise it involving the praxis of the teacher in its action with a view to a better educational quality.

Keywords: permanent training; teacher; educational quality. 


\section{Introducción}

La colectividad Latinoamericana atraviesa tiempos de ruptura, cambios que llevan a apostar a la necesidad de procesos de transformación en los diferentes ambientes políticos, educativo, social, científico, tecnológico, entre otros; donde el "ser humano" quien es capaz de edificar y reconstruir, refundar saberes orientados a transformar las prácticas culturales y sociales de los contextos donde se puedan reconocer valores que hagan del bien común una práctica dirigida a socializar al sujeto para que sea capaz de adecuarse a ese contexto educativo para mejorar la formación permanente en las organizaciones educacionales.

Por esto, la formación permanente en los docentes, desde los bosquejos que hace la UNESCO (1996) "es un proceso educativo dirigido a la revisión y renovación de conocimientos, actitudes y habilidades previamente adquiridas" (pág. 11). De igual manera, González, (2010) refiere que "este proceso abarca actualización, innovación en términos de las exigencias de la sociedad, orientado hacia la excelencia" (pág. 62). En otras palabras, el citado autor alude al tema presentado porque menciona la excelencia que la podemos transferir al concepto de calidad que es el abordado en el estudio mostrado.

Asimismo, el Ministerio del Poder Popular para la Educación, en el Plan Nacional de Formación Permanente (2011-2012), enfatiza "la necesidad de impulsar la formación permanente del docente desde espacios donde sea posible el intercambio permanente de saberes, ideas y opiniones, en ambiente de diálogo propicio para la construcción democrática, plasmados en propuestas de intervención" (pág. 31).

En este sentido, la formación permanente del docente puede ser vista como un espacio en el que se estimule la visión participativa de éste en los lugares educativos, con el propósito de alcanzar una educación que sea capaz de ayudar a formar personas comprometidas con el bienestar individual y el 
de los demás, resaltando actitudes responsables en las relaciones sociales observadas en cada centro educativo.

Debido a lo antes planteado, la concepción de formación docente conlleva a una praxis que busca generar cambios en el individuo, por lo que Gorodokin, (2005) lo apunta como "la acción sobre el sujeto orientado a un cambio en su ser, en el saber hacer, saber obrar y saber pensar, comprendida dentro de un nivel intermedio entre educación e instrucción" (pág. 2). Así, se puede inferir la percepción de los componentes que guardan relación entre saber y práctica, haciendo notar cambios percibidos en la transformación del sujeto que se está formando, respecto a lo afectivo, cognoscitivo y social.

Es por ello, que el proceso formativo es concebido como un tejido con el encuentro humano, donde se busque compartir dialógicamente saberes, concernientes al conocimiento académico y el saber notorio; reflexionando y opinando sobre los mismos lo cual da paso a su construcción e integración individual o colectivamente. De ahí que, el sujeto en formación se apropie en su interacción dialéctica con informaciones, reflexiones y diálogos para que la admisión de los nuevos conocimientos consolide el avance de una educación incluyente y de calidad.

Por esto, la inquietud de elaborar este artículo/ensayo debido a observaciones que inquietan a la autora pues se desea caracterizar la Formación Permanente de los Docentes como Referente de la Calidad, para ofrecer material de revisiones bibliográficas que ayuden al lector a mejorar la calidad educativa en las instituciones formativas.

\section{Formación Permanente del Docente y Humanismo}

Humanismo, según Carrillo, (2016) "es una expresión que para nadie resulta hoy extraña, pues en la vida usual se le escucha con relativa frecuencia" (pág. 71). Es decir, este hecho no implica una comprensión cierta de sus rasgos y alcances, en el ámbito educativo hoy se trata de proporcionar 
conductas que van enfocadas al ser, que te hacen tratar a los demás con humanidad. A decir de Villalpando, (1992) "Los pensadores humanistas fueron entonces intérpretes de nuevas aspiraciones humanas impulsados por la decadencia de la filosofía escolástica, cuyo centro de gravedad era la vida religiosa y la inmortalidad ultraterrena" (pág. 23).

En otras palabras, el humanismo vino a suplantar esa visión del mundo con la reflexión ideológica cuantiosa en productos racionales, en la que prevalecía la idea del hombre como ser humano, genuino y completo. Desde esta postura, es que a partir del Renacimiento se instituye "un nuevo pensamiento pedagógico: ideas y doctrinas de elevado sentido humanista definen desde este período el carácter y el valor de la educación, que adquiere de ese modo las cualidades de autonomía, materialismo e integridad".

Desde, estas premisas y en ese momento histórico, se perfila la necesidad de redimensionar la pedagogía, con un tinte liberador que tomará en cuenta todas las dimensiones del educando, ennobleciendo a la educación como medio para señalarla y ennoblecer a los hombres, para formarlo mejor, librarlo de prejuicios sociales y de falsos orgullos, hacer del educando un ser reflexivo, humanamente formado.

De acuerdo con la teoría humanista, según Carrillo, (ob.cit.) "los estudiantes son entes individuales, únicos, desiguales de los demás; personas con decisión, necesidades personales de crecer, con potencialidad para desplegar actividades y para solucionar problemas creativamente" (pág. 72). Es decir, en su concepción humanista, los estudiantes no son seres que sólo notifican cognitivamente sino personas con cariños, intereses y valores particulares, a quienes debe considerarse seres íntegros y totales.

Desde esta óptica, se asume para el presente artículo que la visión participativa en el proceso de la formación permanente del docente para lograr la calidad educativa está ligada a la filosofía y ética del educador, que 
promueve la formación del educando, debe irse redimensionando en función de los avances y paradigmas educativos.

Por tanto, la autora, utiliza dentro de esta disposición teórica, los aportes ofrecidos por Santos, (2000) sobre algunos rasgos que debe asumir el educador humanista: 1). Ha de ser un maestro interesado en el alumno como persona total; 2). Procura mantener una actitud receptiva hacia nuevas formas de enseñanza; 3). Fomenta en su entorno el espíritu cooperativo; 4). Es auténtico y genuino como persona, y así se muestra ante sus alumnos; 5). Intenta comprender a sus estudiantes poniéndose en el lugar de ellos (empatía) y actuando con mucha sensibilidad hacia sus percepciones y sentimiento; y 6). Rechaza las posturas autoritarias y egocéntricas (pág. 45).

Sin duda, estos rasgos orientan, al menos dos condiciones primordiales que parecen significativas en la educación del siglo presente: conocimiento y valores, que se distribuyen desde el sistema educativo, con la formación de calidad del docente. Desde esta óptica, los docentes humanistas en su constante formación permanente fortalecen las destrezas positivas de sus educandos, estas son designadas potenciales humanos, y ordinariamente centran sus enseñanzas en estas habilidades, una de ellas es la participación en los contextos educativos, lo que hace que manifiesten el deseo de ayudar a las personas a tratar con los demás más apropiadamente.

\subsection{Plan Nacional de Formación Permanente}

En este momento, el conjunto de reformas educativas de los países latinoamericanos ha preferido focalizar sus esfuerzos en la "formación" de docentes, en ocasiones fuera de un contexto de políticas, estrategias y programas de formación permanente. Los recursos invertidos no han mostrado coherencia con la mejora de los resultados de aprendizaje de los estudiantes y ni con cambios en la gestión de las escuelas. 
Visto de esta manera, los docentes son uno de los factores más importantes del proceso educativo. Por ello, a juicio de Carrillo, (ob.cit.) "su calidad profesional, desempeño laboral, compromiso con los resultados, etc., son algunas de las preocupaciones centrales del debate educativo que se orienta a la exploración de algunas claves para lograr que la educación responda a las demandas de la sociedad actual..." (pág. 79). En otras palabras, el desempeño docente, en la actualidad busca consenso acerca de que la formación inicial y permanente de docentes es un elemento de calidad de primer orden del sistema educativo. No es posible hablar de mejora de la educación sin atender el desarrollo profesional de los maestros.

En nuestra cotidianidad, pareciera vislumbrarse dos imágenes del "buen maestro", la primera, el docente cuya visión y vocación de servicio llegan hasta la comunidad, y la segunda, el profesional que cumple cabalmente sus obligaciones dentro de los límites del aula de clases. Sin embargo, asumimos en el marco de este trabajo la caracterización sustentada por Giroux, (1997), que se refiere a los maestros como "Intelectuales Transformativos la cual considera a los docentes como pensadores-investigadores de la educación, capaces de producir conocimiento" (pág. 84).

En otras palabras, si cumplimos, en la práctica, con garantizar una preparación integral, que desarrolle contenidos técnicos, destrezas diversas, aprendizaje continuo, conciencia comprometida en la búsqueda de una sociedad más justa, responsable, todo esto bajo cánones eminentemente democráticos, estaremos cumpliendo con la reivindicación de la educación como proceso social que manifieste a las características y necesidades de la sociedad para lograr el desarrollo pleno del ser humano.

\subsection{La Práctica Formativa y sus Actualizaciones}

El vínculo existente en el docente referido a planificaciones, programas y aspiraciones educativas, lo llevan a investigar, aprender, realizar cursos y 
talleres orientados a esquemas de formación permanente específica, en determinadas áreas, con el objetivo de definir perfiles que la institución educativa considere pertinentes para intervenir en los problemas académicos que implican el bajo rendimiento de los estudiantes. Al incorporar un modelo de formación o capacitación "se hace para que el profesional pueda desarrollarse en un marco flexible y competente", haciéndose imprescindible la participación de distintos factores con ejercicio curricular, incidente en el proceso formativo y se establezca como una columna en esta transformación.

Según lo expresado por Marcelo, (2015) "si se busca promover una formación con impacto en las aulas, debe haber respaldo a las transformaciones que se proponen, recursos materiales y un mejoramiento continuo para que el cambio sea sustentable y sostenible en el tiempo, acompañado de la voluntad política y de consensos" (pág. 159). O sea, de nada sirve proponer cambios y transformaciones en las aulas si no se les provee de herramientas a la vez de una formación permanente continua donde se estén actualizando respecto a las nuevas tendencias educativas.

\subsubsection{La Modernización de los Docentes para una Educación de Calidad}

La educación basada en la calidad es según, Tejada y Giménez (2011) "la orientación artesanal, académica, tecnológica, práctica y la orientación critico-social" (pág. 24). Interpretando los supuestos, según estos autores, por un lado; la orientación artesanal, "es vista como el proceso de transferencia generacional donde la persona obedece a un orden mecanicista y sistemático repitiendo esquemas de autoridad, con imposición de ideas y de conductas de aprendizaje limitados por el tiempo y el espacio que condicionan la racionalidad práctica de la didáctica". En términos generales la didáctica se impone de forma de transferencia con obediencia y operando la sistematicidad en tiempo y espacio. 
En este orden, la orientación académica, "concibe al profesor como un experto en su disciplina con una acción que gira en torno a la materia que enseña, aplicando el uso de modelos educativos en dos vertientes, enciclopédico y comprensivo". Es decir, el enciclopédico abarca lo importante del conocimiento, el segundo es la estrategia de enseñanza buscada para que se dé la razón lógica y haya la transformación del conocimiento para ubicarlo en la realidad.

Otra forma de contribuir a la calidad educativa, está en la orientación tecnológica, la cual considera "al profesor experto en el dominio de técnicas estrategias del proceso-enseñanza, considerando destrezas y habilidades para dar alternativas en el seguimiento de la razón práctica". Sin embargo, la orientación personalista, centra la atención sobre el que enseña, aprende de sí mismo y se identifica con las necesidades, valores y cultura de una sociedad., enfatizando el carácter personal de la educación donde el profesor toma conciencia de sí mismo, dando un carácter formativo más que informativo a lo que se enseña y se aprende en el aula de clases.

Ahora bien, la orientación práctica, se fundamenta "en la experiencia y creatividad del profesor para enfrentar y desarrollar escenarios claros y específicos en el contexto empírico". Es decir, intervienen varios factores entra en el aprendizaje, como investigar en el aula, toma de decisiones planificadas, y el poseer capacidad para relacionar e interactuar la enseñanza en el ámbito que le circunda o sea la realidad que emerge de su realidad.

Por último, la orientación crítico-social, "ve al profesor como el formador, experto del contexto, que reflexiona sobre la realidad fenomenológica y toma decisiones que permiten facilitar el conocimiento en la realidad que vive el alumno". En otras palabras, esta orientación va a permitir intervención y transformación de ese contexto, siendo capaz de ubicar la realidad que constituye la base de los contenidos de manera permanente, los cambios suceden tomando en cuenta el perfil del estudiante, el desempeño del docente, 
lo social y las orientaciones sugeridas por el coordinador institucional basadas en la contextualización a la cual se pertenezca.

En efecto, estas orientaciones han consentido que la formación permanente de docentes de la educación, se centren en la expectativa didáctica utilizada para desplegar su trabajo académico, sin perder de vista los métodos, modelos educativos que se requieren en las instituciones e integrar procesos de investigación, diálogo e intervención en la profesionalización de la calidad docente.

Otro contribuyente al tema es Coll y Solé (1997) "la concepción constructivista, parte de la consideración socializadora de la educación escolar, donde cualquiera de los profesores expertos, deba contar con la reflexión sobre lo que hace y por qué lo hace..." (pág. 23). Como complemento, este último modelo envuelto en mundo globalizado, hace que "la educación realice planteamientos continuos de reformas educativas para afrontar los retos que permitan optimizar las condiciones de calidad, equidad y eficiencia". En síntesis, la formación permanente de los docentes como referente de calidad llevaría a la optimización de las organizaciones educativas en busca de cumplir con la transformación y avances en lo que a materia educativa se refiere.

\subsection{El Rol del Docente}

El docente al desempeñar su rol juega un papel primordial al trasmitir habilidades, generar conocimientos en todos sus campos y desarrollar actitudes para un cambio social. Por lo anterior, el docente deberá tener "un carácter de flexibilidad, reflexivo y crítico de su ser y saber, de cómo aprende, de qué aprende y para qué aprende, lo que admite establecer hechos prácticos fundamentados en la teoría". Para así favorecer la socialización y profesionalizar su labor como docente. Sin embargo, partiendo del sentido socializador de la educación, el docente con sus experiencias educativas 
proporciona elementos de utilidad para la planificación, seguimiento y evaluación del proceso educativo. Hasta el momento el conocimiento del cambio en el ámbito educativo esboza, la necesidad de adecuarse a las nuevas formas de producción del conocimiento, de su presentación y de sus usos en relación con el medio social; el aprendizaje que se busca a través de la internalización y apropiación del conocimiento, a través de la constante aplicación que según Delors, (1996) "abarque los cuatro pilares fundamentales: el aprender a conocer, el aprender a hacer, el aprender a vivir juntos y el aprender a ser" (pág. 16-22).

En cuanto a la reestructuración curricular, involucra la consideración de algunos aspectos y características del contexto cultural, histórico y económico de cada país, dando una nueva visión y un nuevo modelo de enseñanza enfocado en el estudiante, al vincular el saber teórico y práctico tradicional con la ciencia y la tecnología de vanguardia, propiciándose así, nuevos tipos de vínculos, y de colaboración con la escuela, comunidad y con los más amplios y necesitados sectores de la sociedad.

De la crisis y necesidades educativas en materia de formación del docente Pérez, (2004), "la educación debe recobrar y fortalecer sus dimensiones" (pág. 24). En estos tiempos de individualismo, en los que se opacan las grandes ideas con la insensibilidad y la injusticia, se necesitan con urgencia a los grandes predicadores de la educación.

Hoy hay demasiado miedo al futuro, miedo a asumir en serio nuestra vocación de constructores de la historia, miedo de sumergirse en el cauce profundo de la vida. "Se Necesitan educadores profetas, capaces de leer con los ojos y el corazón de Dios la profunda crisis de este mundo, para poder decir con valor y con pasión lo que Dios quiere y espera que se diga. Profetas que encarnen en las vidas y los valores ideales para que las palabras sean hechos, testimonio". 
Sobre el asunto, la función del docente transmite actitudes reflexivas y críticas hacia el cambio y la innovación, examinando su papel en el modelo que tiene la institución educativa en su trayecto curricular, tal y como la estructura del sistema educativo, constituyen funciones organizacionales, de construcción cognitiva, de ambientación adecuada y de actividades de enseñanza-aprendizaje. En este contexto, el papel del docente no se ancla solo a la identificación de un método educativo, sino que además, toma en cuenta el transitar de distintas corrientes pedagógicas que sustentan la función social como integradora de sociedades futuras.

\section{Metodología}

La revisión teórica mostrada se realizó tomando en cuenta diferentes documentos que pensamos sirven de ayuda para la temática a tratar con sus respectivas bibliografías que sirven de referente al lector, por tanto, se ubica en una investigación de tipo documental, aludiendo los postulados de Palella y Martins (2010) define: "La investigación documental se concreta exclusivamente en la recopilación de información en diversas fuentes. Indaga sobre un tema en documentos -escritos u orales-..." (pág. 90). En otras palabras, la información mostrada se seleccionó de acuerdo a la importancia y relevancia para la indagación presentada, a favor de cubrir las expectativas del lector.

\section{Consideraciones Finales}

En síntesis, la función que envuelve al docente para favorecer la formación permanente adecuada de los estudiantes debe integrar no sólo la episteme disciplinaria sino además implica una preparación adecuada para el desenvolvimiento en su conocimiento con destrezas pertinentes donde motive al estudiante para un aprendizaje significativo. 
Los docentes desde sus diversos ambientes hacen necesaria una constante formación que les permita reforzar la orientación e inducción tanto en los modelos de innovación curricular, como a la calidad de la profesión y al aprendizaje. La institución debe integrar en el ambiente laboral las condiciones adecuadas para ofrecer procesos de enseñanza y aprendizaje de calidad reconociendo la pertinencia del trabajo escolar por lo que en ocasiones pudiera parecer que se realizan de forma desarticulada entre los contenidos de una unidad de aprendizaje, además de que difícilmente promueve el trabajo inter o multidisciplinario.

Lo que se pretende es, que de manera integral con la formación permanente del docente, se garantice la participación en la construcción colectiva del saber pedagógico a través de la estructuración de cursos, talleres, con la inclusión de políticas, planes, y programas que capaciten a los docentes para una mejor enseñanza aprendizaje en el aula. Con el fin de guiar a caminos propios la enseñanza-aprendizaje y crear condiciones para el acompañamiento en las prácticas pedagógicas de los docentes en sus aulas.

\section{Referencias}

Carrillo, M. (2016). Participación Activa de los Docentes en el Proceso de Formación Permanente e Investigación desde una Perspectiva Crítico Reflexiva. Tesis Doctoral. Universidad Nacional Experimental "Rafael María Baralt".

Coll y Solé (1997). El constructivismo en el aula, Grao, España.

Delors, J. (1996). La educación encierra un tesoro. Informe a la UNESCO de la Comisión Internacional sobre la Educación para el siglo XXI. Correo de la UNESCO, Col. Educación y cultura para el nuevo milenio, México. 
Giroux, H. (1997). La Pedagogía Crítica. Revista Electrónica Sinéctica, núm. 29, agosto-enero, 2006, pp. 83-87 Instituto Tecnológico y de Estudios Superiores de Occidente Jalisco, México.

González, E. (2010). Manual sobre Participación y Organización para la Gestión Local. Foro Nacional por Colombia. Cali.

Gorodokin I. (2005). Formación docente y su relación con la epistemología. [Artículo en Línea]. Recuperado de:

https://dialnet.unirioja.es/servlet/articulo?codigo $=3197461$

Marcelo, C. (2015). El ABC y D de la Formación Docente. Madrid. NARCEA. Ministerio del Poder Popular para la Educación. Plan Nacional de Formación Permanente 2011-2012. Dimensión Reflexiones Críticas Sobre el Proceso Educativo. Módulo de Formación: Pedagogía y Didáctica Crítica. Educación Universitaria para la Emancipación.

Palella, S. y Martins, F. (2010). Metodología de la investigación cuantitativa. 2da Edición. FEDEUPEL.

Pérez Esclarín, A. (2004). Educar para Humanizar. Narcea, S.A. Madrid España.

Santos, M. (2000). La escuela que aprende. Ed. Morata. Madrid.

Tejada, Giménez, V. y otros (2011). Formación de Formadores. Madrid. Paraninfo.

UNESCO (1996). La Educación Encierra un Tesoro. Informe a la UNESCO de la Comisión Internacional sobre la Educación para el siglo XXI. Santillana Ediciones UNESCO, Madrid.

Villalpando, B. (1992). Historia del Humanismo. Sirio S.A. Málaga. 


\section{Johana Carolina Peña Lozada}

e-mail: johanacarol@yahoo.com

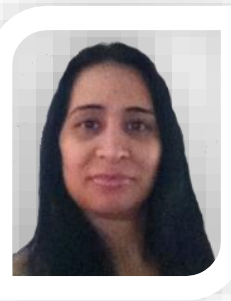

Nacida en Valera, Estado Trujillo, Venezuela. Licenciada en Administración (Universidad de los Andes. Extensión Trujillo). Técnico Superior en Educación Integral (IUTEMBI). Licenciada en

Educación Mención Educación para el trabajo y Desarrollo Endógeno (Universidad de los Andes, extensión Trujillo). Especialista en Gerencia de Recursos Humanos (Universidad Nacional Experimental Simón Rodríguez). Actualmente presentando Tesis para Doctora en Educación (UNERMB). Docente de Aula en la Escuela Técnica Salesiana Santo Tomas de Aquino. (Valera). Docente de Aula. Coordinadora de Planificación y Evaluación. Coordinadora de la Especialidad Comercios y Servicios Administrativos. Subdirectora Técnica en la (ETRZ Mons. Estanislao Carrillo). Carvajal. 